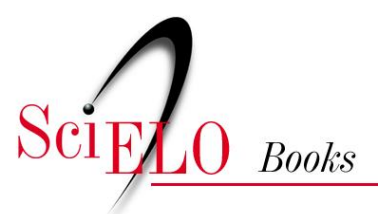

\title{
Ordem Beloniformes
}

\author{
Ana Cristina Teixeira Bonecker \\ Claudia Akemi Pereira Namiki \\ Márcia Salustiano de Castro \\ Paula Nepomuceno Campos
}

\section{SciELO Books / SciELO Livros / SciELO Libros}

BONECKER, ACT., et al. Ordem Beloniformes. In Catalogo dos estágios iniciais de desenvolvimento dos peixes da bacia de Campos [online]. Curitiba: Sociedade Brasileira de Zoologia, 2014, pp. 153-160. Zoologia: guias e manuais de identificação series. ISBN 978-85-98203-10-2.

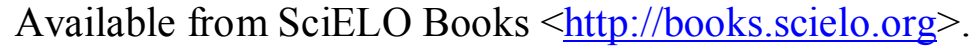

\section{(2)(1)(2)}

All the contents of this chapter, except where otherwise noted, is licensed under a Creative Commons Attribution-Non Commercial-ShareAlike 3.0 Unported.

Todo o conteúdo deste capítulo, exceto quando houver ressalva, é publicado sob a licença Creative Commons Atribuição Uso Não Comercial - Partilha nos Mesmos Termos 3.0 Não adaptada.

Todo el contenido de este capítulo, excepto donde se indique lo contrario, está bajo licencia de la licencia Creative Commons Reconocimento-NoComercial-CompartirIgual 3.0 Unported. 


\section{Ordem Beloniformes}

A ordem Beloniformes é composta por cinco famílias e 227 espécies. Algumas espécies são restritas a ambientes de água doce e outras habitam estuários e regiões marinhas. Os representantes dessa ordem dominam a zona epipelágica nas regiões tropicais e subtropicais. As características comuns da ordem são: localização das nadadeiras dorsal e anal na parte posterior do corpo, nadadeira pélvica abdominal com seis raios e ausência de espinhos nas nadadeiras.

Nesse estudo a ordem Beloniformes é representada pelas famílias Scomberesocidae, Hemiramphidae e Exocoetidae. 


\section{Família Scomberesocidae}

A família Scomberesocidae é marinha e epipelágica. Ocorre nos mares tropicais e temperados. Compreende dois gêneros com duas espécies cada. A principal característica que separa essa família das demais da ordem Beloniformes é que a maxila superior é um pouco alongada.

No Brasil já foram identificadas três espécies nas fases de larva e adulto: Scomberesox saurus (Walbaum, 1792), Scomberesox scombroides (Richardson, 1843) e Scomberesox simulans (Hubbs \& Wisner, 1980). Nesse estudo é contemplada a espécie Scomberesox sp. 


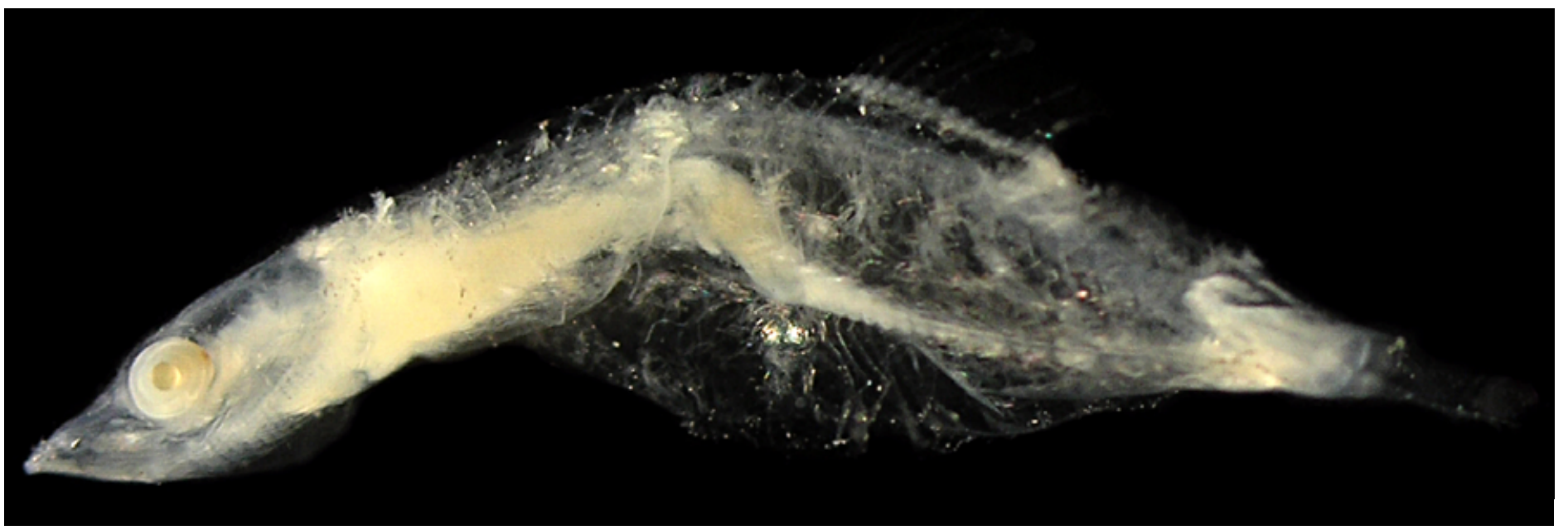

Figura 90: Scomberesox sp. DZUFRJ 20206; Flexão; CP 10,0 mm.

\section{Scomberesox sp.}

As larvas de Scomberesox possuem o corpo alongado (64 a 68 miômeros) e fino. O intestino é longo alcançando mais da metade do corpo. Possuem o corpo todo pigmentado. A nadadeira caudal é bem desenvolvida desde os estágios larvares iniciais.

Tamanho: flexão 10,0 mm.

Habitat: todas as espécies registradas na literatura são marinhas e epipelágicas. Ocorre em águas tropicais e temperadas, em regiões oceânicas.

\section{Georreferrenciamento}

\begin{tabular}{|c|c|c|c|c|c|c|c|c|}
\hline DZUFRJ & Latitude (S) & Longitude (W) & Data & $\begin{array}{c}\text { Tipo de } \\
\text { arrasto }\end{array}$ & $\begin{array}{c}\text { Profundidade } \\
\text { de coleta }\end{array}$ & Rede & $\begin{array}{c}\text { Malha } \\
\text { ( } \boldsymbol{\mu m} \text { ) }\end{array}$ & $\begin{array}{c}\mathbf{N}^{\circ} \text {. de } \\
\text { inds. }\end{array}$ \\
\hline 20206 & $22^{\circ} 08^{\prime} 01,8^{\prime \prime}$ & $039^{\circ} 37^{\prime} 30,8^{\prime \prime}$ & $03 / 12 / 2002$ & vertical & $50 \mathrm{~m}$ & cilíndrico-cônica & 500 & 1 \\
\hline
\end{tabular}

Referências: Hardy \& Collette, 2006; Fahay, 2007. 


\section{Família Hemiramphidae}

A família Hemiramphidae é marinha e epipelágica, também possui representantes de água doce. Ocorre nos oceanos Atlântico, Índico e Pacífico. Compreende duas subfamílias e 12 gêneros com aproximadamente 109 espécies. A principal característica que separa essa família das demais da ordem Beloniformes é que a maxila inferior é normalmente muito alongada e a maxila superior é muito curta e triangular.

No Brasil já foram identificadas sete espécies nas fases de larva e adulto. Nesse estudo são contempladas as espécies Euleptorhamphus velox e Hyporhamphus unifasciatus. 


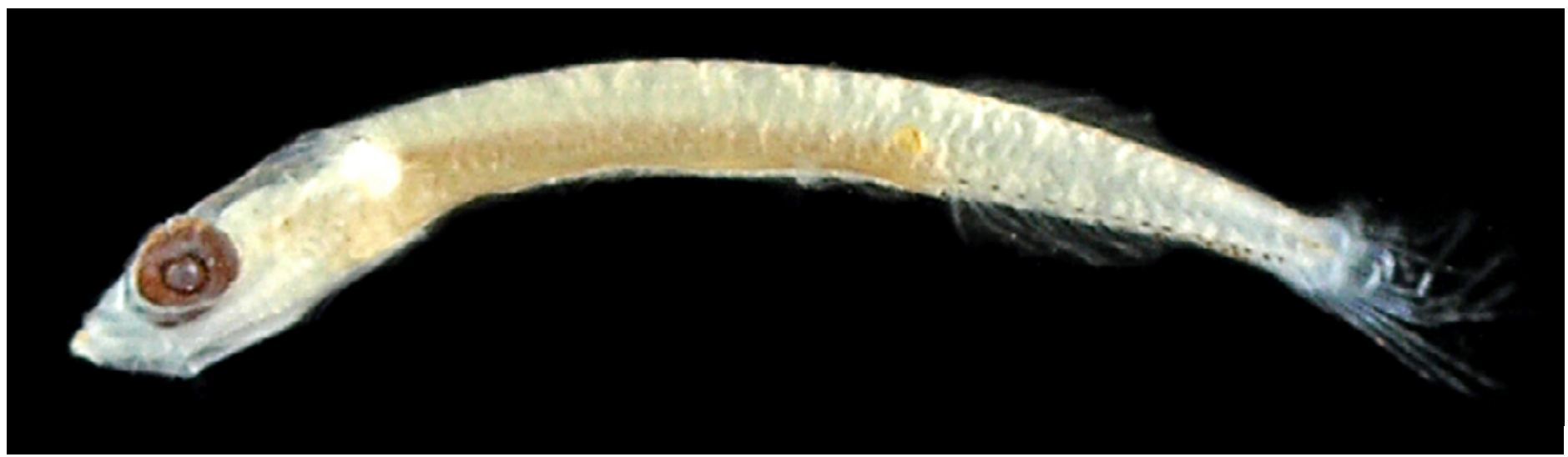

Figura 91: Euleptorhamphus velox. DZUFRJ 25291; Flexão; CP 7,3 mm.

\section{Euleptorhamphus velox Poey, 1868}

Possui o corpo muito alongado (aproximadamente 71-73 miômeros) e fino. 0 intestino é longo alcançando aproximadamente $70 \%$ do corpo. A maxila inferior é longa desde os estágios iniciais de desenvolvimento. As bases das nadadeiras dorsal e anal são grandes. Raios da dorsal: 21-24. Raios da anal: 20-24. Apresenta pigmentação na margem dorsal do intestino formando uma faixa atrás do olho. A margem dorsal do corpo também é muito pigmentada formando duas faixas contínuas (uma de cada lado do corpo) desde a cabeça até a cauda.

Tamanho: pré-flexão 1,5-2,0 mm; flexão 4,5-8,5 mm.

Habitat: espécie marinha e epipelágica. Ocorre em águas tropicais principalmente em regiões oceânicas ou próximas a ilhas.

Nome vulgar: Agulhinha.

\section{Georreferrenciamento}

\begin{tabular}{|c|c|c|c|c|c|c|c|c|}
\hline DZUFR & Latitude (S) & Longitude (W) & Data & $\begin{array}{c}\text { Tipo de } \\
\text { arrasto }\end{array}$ & $\begin{array}{c}\text { Profundidade } \\
\text { de coleta }\end{array}$ & Rede & $\begin{array}{c}\text { Malha } \\
(\boldsymbol{\mu m})\end{array}$ & $\begin{array}{c}\mathbf{N}^{\circ} \text {. de } \\
\text { inds. }\end{array}$ \\
\hline 360 & $22^{\circ} 38^{\prime} 25,0^{\prime \prime}$ & $040^{\circ} 17^{\prime} 41,0^{\prime \prime}$ & $19 / 05 / 2002$ & oblíquo & $40 \mathrm{~m}$ & bongô & 330 & 2 \\
\hline 371 & $22^{\circ} 33^{\prime} 37,0^{\prime \prime}$ & $040^{\circ} 19^{\prime} 10,0^{\prime \prime}$ & $17 / 05 / 2002$ & oblíquo & $50 \mathrm{~m}$ & bongô & 500 & 1 \\
\hline 450 & $22^{\circ} 42^{\prime} 06,0^{\prime \prime}$ & $040^{\circ} 14^{\prime} 26,0^{\prime \prime}$ & $19 / 05 / 2002$ & oblíquo & $50 \mathrm{~m}$ & bongô & 500 & 1 \\
\hline 1336 & $22^{\circ} 06^{\prime} 37,8^{\prime \prime}$ & $039^{\circ} 49^{\prime} 44,8^{\prime \prime}$ & $10 / 05 / 2002$ & oblíquo & até a termoclina & bongô & 330 & 1 \\
\hline 1382 & $22^{\circ} 08^{\prime} 149^{\prime \prime}$ & $039^{\circ} 46^{\prime} 34,6^{\prime \prime}$ & $11 / 05 / 2002$ & oblíquo & até a termoclina & bongô & 330 & 2 \\
\hline 25291 & $21^{\circ} 57,12^{\prime}$ & $039^{\circ} 37,32^{\prime}$ & $18 / 06 / 2003$ & horizontal & superfície & nêuston & 500 & 2 \\
\hline
\end{tabular}

Referências: Collette, 2006; Fahay, 2007. 


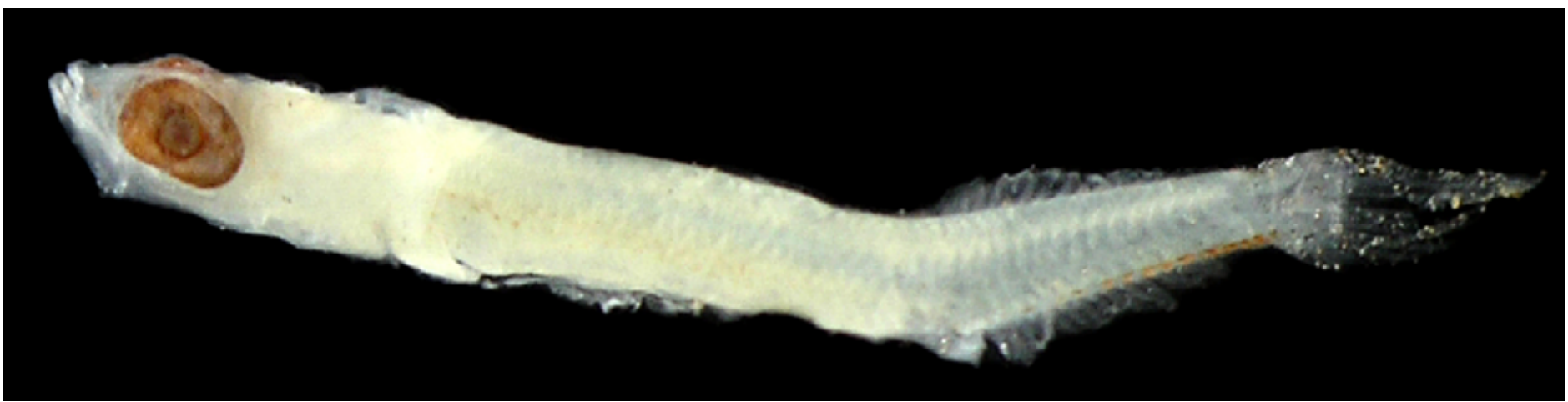

Figura 92 - A: Hyporhamphus unifasciatus. DZUFRJ 25293; Flexão; CP 4,5 mm.

\section{Hyporhamphus unifasciatus (Ranzani, 1841)}

Possui o corpo alongado e fino. $O$ número total de vértebras varia entre 50-54. O intestino é longo alcançando mais da metade do corpo. Raios da dorsal: 13-16. Raios da anal: 14-18. Possui pigmentação na região do intestino, nas extremidades das maxilas, na região inferior do opérculo. A margem dorsal do corpo possui blocos de pigmentos formando uma faixa descontínua desde a cabeça até a cauda. Em larvas maiores esses pigmentos formam uma linha pontilhada. Possui uma linha descontínua de pigmentos na linha lateral e um pigmento no meio do pedúnculo caudal.

Tamanho: flexão 4,5 mm; pós-flexão 13,5 mm.

Habitat: espécie marinha e epipelágica. Ocorre principalmente em regiões costeiras.

Nome vulgar: Agulha branca.

\section{Georreferrenciamento}

\begin{tabular}{|c|c|c|c|c|c|c|c|c|}
\hline DZUFRJ & Latitude (S) & Longitude (W) & Data & $\begin{array}{l}\text { Tipo de } \\
\text { arrasto }\end{array}$ & $\begin{array}{c}\text { Profundidade } \\
\text { de coleta }\end{array}$ & Rede & $\begin{array}{l}\text { Malha } \\
(\mu \mathrm{m})\end{array}$ & $\begin{array}{l}N^{\circ} \text {. de } \\
\text { inds. }\end{array}$ \\
\hline 1188 & $22^{\circ} 07^{\prime} 29,0^{\prime \prime}$ & $039^{\circ} 06^{\prime} 23,5^{\prime \prime}$ & $10 / 05 / 2002$ & oblíquo & $1.000 \mathrm{~m}$ & $\begin{array}{l}\text { cilíndrico- } \\
\text { cônica }\end{array}$ & 500 & 1 \\
\hline 1316 & $22^{\circ} 08^{\prime} 14,9^{\prime \prime}$ & $039^{\circ} 46^{\prime} 34,6^{\prime \prime}$ & $11 / 05 / 2002$ & oblíquo & até a termoclina & bongô & 500 & 2 \\
\hline 25292 & $22^{\circ} 02,27^{\prime}$ & $039^{\circ} 43,49^{\prime}$ & $18 / 06 / 2003$ & horizontal & superfície & nêuston & 500 & 1 \\
\hline 25293 & $22^{\circ} 28,52^{\prime}$ & $039^{\circ} 55,47^{\prime}$ & $16 / 06 / 2003$ & horizontal & superfície & nêuston & 500 & 1 \\
\hline
\end{tabular}

Referências: Collette, 2006.

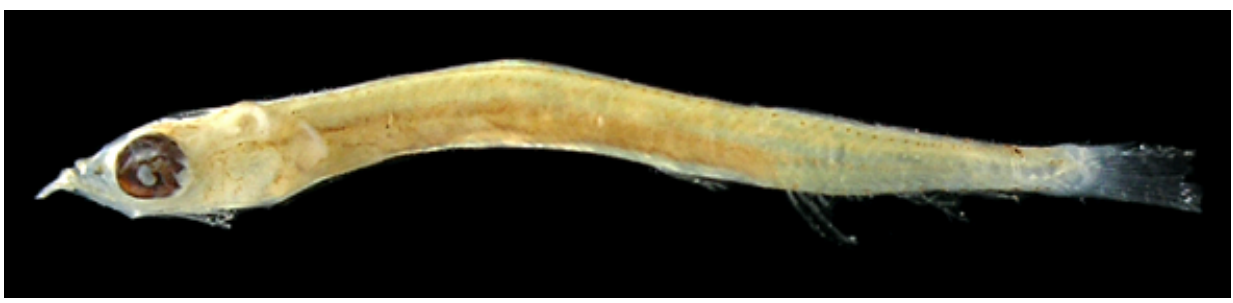

Figura 92 - B: DZUFRJ 25292; Pós-flexão; CP 13,5 mm. 


\section{Família Exocoetidae}

A família Exocoetidae é marinha e epipelágica. Ocorre nos oceanos Atlântico, Índico e Pacífico. Compreende cinco subfamílias e oito gêneros com aproximadamente 52 espécies. A principal característica que separa essa família das demais da ordem Beloniformes é que a maxila inferior é sempre reduzida nas larvas maiores. Algumas espécies possuem barbilhão e nadadeiras peitoral e pélvica muito desenvolvidas.

No Brasil já foram identificadas 12 espécies nas fases de larva e adulto. Nesse estudo é contemplada a espécie Hirundichthys rondeletti. 


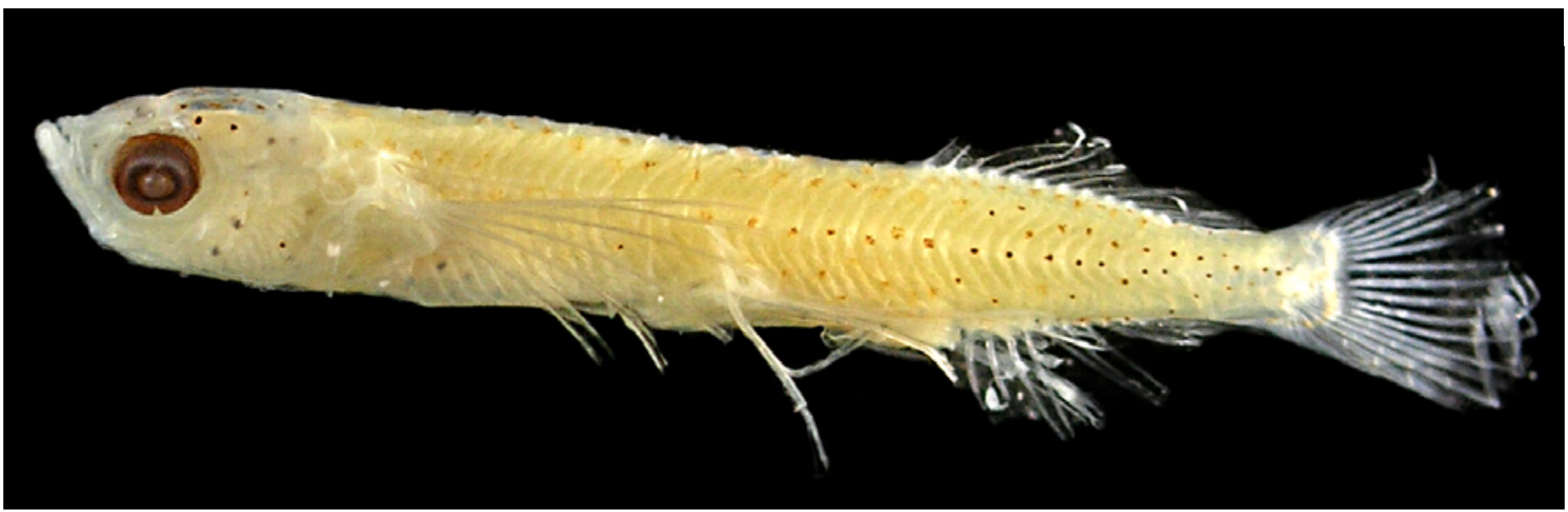

Figura 93: Hirundichthys rondeletti. DZUFRJ 26294; Pós-flexão; CP 13,5mm.

\section{Hirundichthys rondeletti (Valenciennes, 1847)}

As larvas de Hirundichthys podem ser separadas das demais espécies da família Exocoetidae pelo número de raios das nadadeiras dorsal e anal, pela posição dessas nadadeiras e pelo padrão de pigmentação. As larvas dessa espécie possuem 10-12 raios na nadadeira dorsal e 11-13 na anal. O corpo é todo pigmentado e os cromatóforos são grandes. O número de miômeros varia aproximadamente entre 45 e 46.

Tamanho: pós-flexão 13,5 mm.

Habitat: espécie marinha e epipelágica. Ocorre em águas subtropicais em regiões oceânicas.

Nome vulgar: Voador.

Georreferrenciamento

\begin{tabular}{|c|c|c|c|c|c|c|c|c|}
\hline DZUFRJ & Latitude (S) & Longitude (W) & Data & $\begin{array}{c}\text { Tipo de } \\
\text { arrasto }\end{array}$ & $\begin{array}{c}\text { Profundidade } \\
\text { de coleta }\end{array}$ & Rede & $\begin{array}{c}\text { Malha } \\
(\boldsymbol{\mu m})\end{array}$ & $\mathbf{N}^{\circ}$. de inds. \\
\hline 25294 & $22^{\circ} 28,5^{\prime}$ & $039^{\circ} 55,47^{\prime}$ & $16 / 06 / 2003$ & horizontal & superfície & nêuston & 500 & 1 \\
\hline
\end{tabular}

Referências: Cotton \& Comyns, 2006; Fahay, 2007. 